\title{
NIST Metric Pyramid
}

(LC1140 Apr'02)

\section{Reproduction Master}

To ensure accurate scale, do not enlarge or reduce. Reproduce one per 11 "x8.5" sheet. For best results, reproduce on $110 \mathrm{lb}$ index stock, or $67+$ lb vellum.
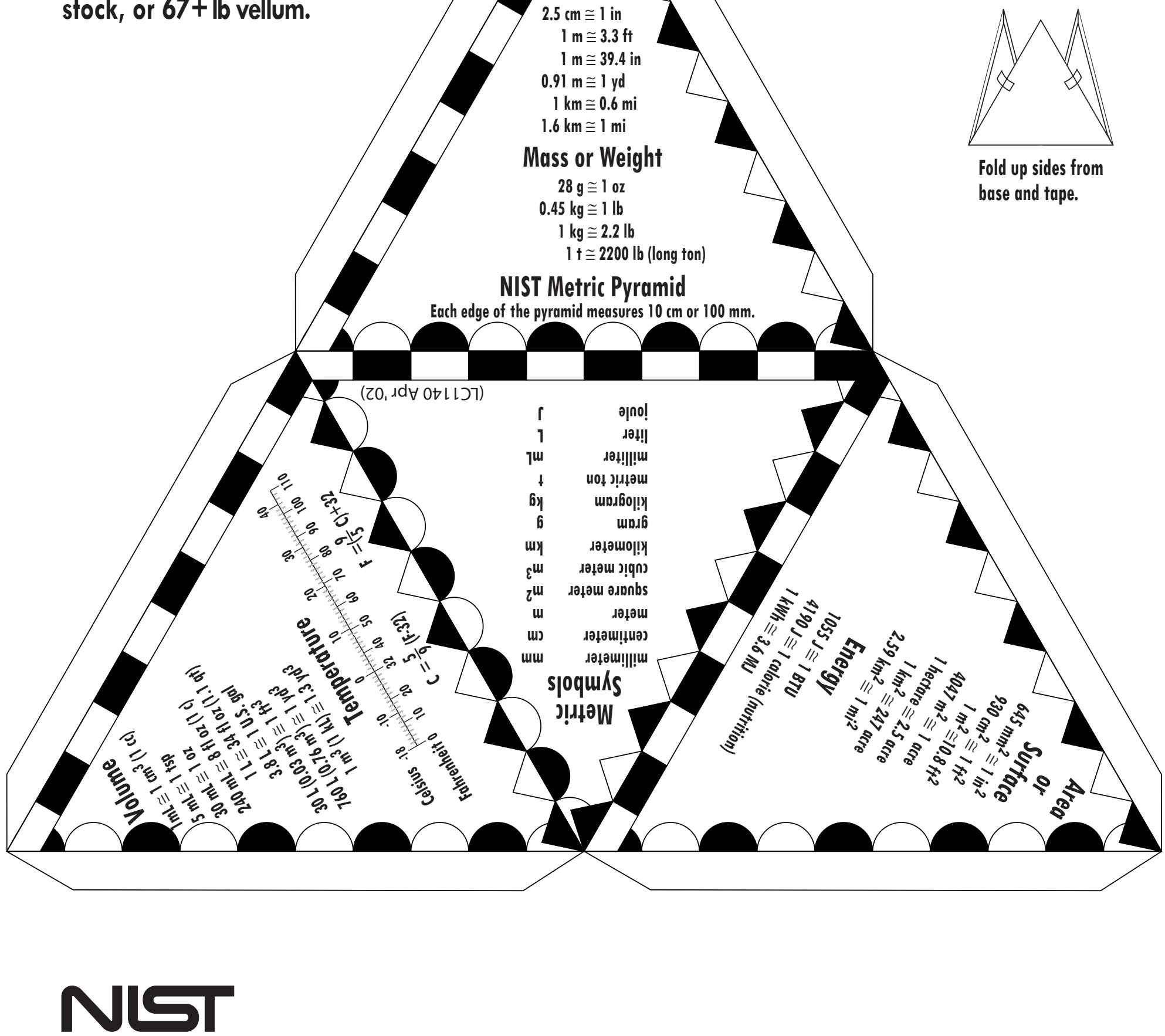

National Institute of Standards and Technology

Technology Administration, U.S. Department of Commerce 